\title{
Nathalie Coilly et Marie-Hélène Tesnière, Le Roman de la rose. L'art d'aimer au Moyen Âge
}

\section{Maria Colombo Timelli}

\section{(2) OpenEdition}

1 Journals

\section{Édition électronique}

URL : https://journals.openedition.org/studifrancesi/2992

DOI : 10.4000/studifrancesi.2992

ISSN : 2427-5856

Éditeur

Rosenberg \& Sellier

\section{Édition imprimée}

Date de publication : 1 juillet 2013

Pagination : 429

ISSN : 0039-2944

\section{Référence électronique}

Maria Colombo Timelli, « Nathalie Coilly et Marie-Hélène Tesnière, Le Roman de la rose. L'art d'aimer au Moyen Âge », Studi Francesi [En ligne], 170 (LVII | II) | 2013, mis en ligne le 30 novembre 2015, consulté le 31 janvier 2023. URL : http://journals.openedition.org/studifrancesi/2992 ; DOI : https://doi.org/ 10.4000/studifrancesi.2992

Ce document a été généré automatiquement le 31 janvier 2023.

\section{(c) (†) $\odot$}

Creative Commons - Attribution - Pas d'Utilisation Commerciale - Pas de Modification 4.0 International - CC BY-NC-ND 4.0

https://creativecommons.org/licenses/by-nc-nd/4.0/ 


\title{
Nathalie Coilly et Marie-Hélène Tesnière, Le Roman de la rose. L'art d'aimer au Moyen Âge
}

\author{
Maria Colombo Timelli
}

\section{RÉFÉRENCE}

NATHALIE COILLY et MARIE-HÉLÈNE TESNIÈRE, Le Roman de la rose. L'art d'aimer au Moyen Âge, Paris, Bibliothèque nationale de France, 2012, pp. 195.

1 L'exposition sur le Roman de la rose (Bibliothèque de l'Arsenal, du 6 novembre 2012 au 17 février 2013) a offert l'occasion pour publier ce beau volume, qui est bien plus qu'un catalogue des pièces présentées: la liste de celles-ci n'occupe en effet qu'une dizaine de pages en appendice (pp. 183-193). N.C. et M.-H.T. ont relevé le véritable défi que constitue une présentation du plus grand succès de lecture du Moyen Âge destinée à un large public, sans pour autant renoncer à une approche scientifique.

2 Le contenu du Roman est d'abord résumé dans sa dualité (N.C., Le 'Roman de la rose': le récit, pp. 19-23), puis examiné du point de vue des diverses lectures auxquelles la partie Guillaume de Lorris et la partie Jean de Meun ont donné lieu (M.-H.T., Arts d'aimer, art d'écrire, art d'interpréter, pp. 43-57); les interprétations et commentaires sur le Roman qui se multiplièrent au Moyen Âge déjà sont aussi rappelés (N.C., 'Senefiance' et sentences: les enseignements du 'Roman de la rose', pp. 83-89; La réception du 'Roman de la rose'), ainsi que la célèbre querelle qui éclata au début du XV siècle (M.-H.T., La Querelle du 'Roman de la rose': «un débat gracieux et non haineux»?, pp. 119-124); l'ampleur exceptionnelle du succès du Roman impose que l'on s'interroge aussi sur les manuscrits, leur fabrication, mise en page, iconographie (N.C., La diffusion du 'Roman de la rose' au Moyen Âge, pp. 139-143), et sur les imprimés, chapitre confié à Martine Lefèvre (La production imprimée: lecture et postérité du 'Roman de la rose', pp. 157-161). Un paragraphe à part, signé par Wilfrid Fauquet, est consacré au Livre des Eschez amoureux d'Evrard de Conty et en 
particulier au manuscrit illustré vers la fin du $\mathrm{xv}^{\mathrm{e}}$ siècle par le Maître d'Antoine Rolin, où une enluminure rend compte d'une partie d'échecs manifestement inspirée du Roman (Le 'Roman de la rose' sur un échiquier, pp. 113-117).

3 Un richissime dossier d'images accompagne chaque chapitre: soulignons, au-delà de la beauté des reproductions, la qualité des légendes qui, loin de se borner à donner les informations essentielles sur chaque enluminure, fournissent des commentaires développés permettant de la situer tant dans le manuscrit que dans le texte et éventuellement dans la tradition textuelle et iconographique médiévale.

4 Une bibliographie sur le Roman de la rose ne saurait trouver place dans un volume de ce genre: raison de plus pour être reconnaissant aux deux responsables d'avoir essayé quand même d'offrir des points de repère essentiels par la liste des ouvrages qu'elles ont utilisés; celle-ci contient des renvois aux bibliographies bien connues des spécialistes (Arden 1993 et Braet 2006), les éditions et traductions du Roman les plus qualifiées, et un choix d'études; s'ajoute encore une petite section consacrée aux éditions des textes médiévaux cités.

5 Véritable monument de la littérature française médiévale qu'on a pu comparer à la Commedia de Dante de par sa fortune, le Roman de la rose méritait bien une exposition, dans le sillage du projet en partenariat entre la Johns Hopkins Université et la BnF (cf. le site http://romandelarose.org); notre reconnaissance va aussi à la BnF et aux deux commissaires pour l'avoir organisée et en avoir offert plus que l'essence dans ce très beau livre. 